\title{
Epidemiology of penicillin resistant Neisseria gonorrhoeae
}

\author{
C A Ison, C S F Easmon
}

\begin{abstract}
Objective-To study the epidemiology of Neisseria gonorrhoeae that exhibit both chromosomal and plasmid-mediated resistance to penicillin.
\end{abstract}

Materials and methods-A total of 1589 strains of $N$ gonorrhoeae isolated from patients attending St Mary's Hospital, London were tested for both their susceptibility to penicillin and for their auxotype and serotype.

Results-Of the 940 non-penicillinase producing $\boldsymbol{N}$ gonorrhoeae, 840 were considered penicillin sensitive (MIC $\leq 0.5 \mathrm{mg} / 1$ ) and 100 were chromosomally-mediated resistant $N$ gonorrhoeae (CMRNG), (MIC $\geq 1.0 \mathrm{mg} / 1$ ). Of the 649 penicillinase producing $N$ gonorrhoeae (PPNG), 429 carried the 4.4 megadalton (MDa) penicillinase encoding plasmid and 220 carried the 3.2 MDa plasmid. CMRNG were predominantly serogroup IB (90\%). PPNG with $3 \cdot 2 \mathrm{MDa}$ plasmid were the only group more often serogroup IA (58\%) than IB (42\%). Serovar IA$1 / 2$ and requirement for arginine, hypoxanthine and uracil (AHU) were associated with increased susceptibility to penicillin whereas serovar IB-5/7 was associated with decreased susceptibility in nonPPNG. There was a significant difference in the distribution of the IA and IB serovars between PPNG carrying either the $4.4 \mathrm{MDa}$ or $3.2 \mathrm{MDa}$ plasmid. AHU and PAOU requiring strains were not found among PPNG and were uncommon among CMRNG.

Conclusion-Some clear associations have been found but the pattern among PPNG appears more complex and in most instances could be related to clusters of a single strain over a short time span.

Introduction

Resistance to penicillin in $N$ gonorrhoeae can be

Department of Medical Microbiology, St Mary's Hospital Medical School, Norfolk Place, Paddington, London W2 1PG, UK

C A Ison, C S F Easmon either chromosomally or plasmid mediated. ${ }^{1}$ Chromosomal resistance is the result of low-level increases at multiple loci. Such resistance was first described in $1958^{2}$ but could be overcome by increased therapeutic dosage. Plasmid-mediated resistance results from the presence of a TEM-1 type penicillinase and was first described in $1976^{3-6}$ encoded on plasmids of $3.2 \mathrm{MDa}$ and $4.4(\mathrm{MDa})^{7}$ in $N$ gonorrhoeae. Penicillinase-producing $N$ gonorrhoeae (PPNG) are now common and their high level of resistance often results in failure to penicillin therapy. Other penicillinase encoding plasmids have been reported but are neither common nor widespread. In more recent years infections caused by chromosomally-resistant $N$ gonorrhoeae (CMRNG) have increased ${ }^{89}$ and begun to present therapeutic problems. ${ }^{10}$

The epidemiology of antibiotic resistant strains has been poorly studied until recent years because of the lack of a suitable typing system. Typing by nutritional requirement, auxotyping and plasmid profiles has been used successfully but lacks sufficient discrimination when used alone. The production of a panel of monoclonal antibodies raised to epitopes on the major outer membrane protein, $\mathrm{PI},{ }^{11}$ and used in a coagglutination system ${ }^{12}$ has provided a reliable, reproducible and discriminative typing scheme. This typing scheme has been used extensively to study populations of $N$ gonorrhoeae of differing geographical origin and antibiotic susceptibility. ${ }^{1314}$

We have used this system to study the association of susceptibility to a range of antibiotics with the serotype of non-penicillinase-producing $N$ gonorrhoeae (nonPPNG), ${ }^{15}$ to examine PPNG isolated in our hospital between $1978-87^{16}$ and to study gonococci from Bahrain. ${ }^{17}$ The aim of this study is to compare and contrast the epidemiology of penicillin resistant strains either chromosomally or plasmidmediated. Of the strains used in this analysis 650 of 940 nonPPNG ${ }^{15}$ and 634 of 649 PPNG $^{16}$ have been described previously.

Materials and methods

Strain population

All strains of $N$ gonorrhoeae tested were isolated from patients attending the Genitourinary Medicine Clinic at St Mary's Hospital, London. Nine hundred 
and forty strains of non-PPNG were collected between 1984-1988. These strains were a sample of 20 strains per month, the first 10 isolates from men and women, which we have shown previously can be used to monitor major trends. ${ }^{18} \mathrm{~A}$ total of 649 PPNG were collected between 1978 and 1989. These were strains that were retrievable from storage for serotyping and represent $60 \%$ of total PPNG isolated.

\section{Isolation and identification}

All strains were isolated on GC agar base (BBL) supplemented with $1 \%$ IsoVitaleX (BBL), vancomycin (3 mg/1), colistin (1000 units/1), trimethoprim $(5 \mathrm{mg} / \mathrm{l})$ and amphotericin $(1.5 \mathrm{mg} / \mathrm{l})$. Cultures were incubated for up to 48 hours at $36^{\circ} \mathrm{C}$ in $7 \%$ carbon dioxide. Strains of $N$ gonorrhoeae were identified using either carbohydrate utilisation tests or by immunofluorescence (GC Microtrak, Syva). All further subcultures were made on GC agar base (Difco) with $1 \%$ IsoVitaleX with no antibiotics added. Strains were stored in the vapour phase of liquid nitrogen in $15 \%$ glycerol broth until required.

\section{Serotyping}

Serotyping was performed using a panel of twelve monoclonal antibodies raised to epitopes on the two types of the major outer membrane protein, PI. The antibodies were used in a coaggulation system described previously ${ }^{15-17}$ using the nomenclature of Knapp et al. ${ }^{12}$ Strains which belonged to either serovars IA-1 and IA-2 or IB-5 and IB-7 were considered as single serovars because they differ only in a single epitope $\mathrm{e}^{1215}$ and show similar characteristics.

\section{Auxotyping}

The nutritional requirements for growth were determined using the defined media and method of Copley and Egglestone. ${ }^{19}$ Strains were scored for the requirement for proline, arginine, hypoxanthine, uracil, methionine, and histidine. The requirement for ornithine as an alternative substrate to arginine was also tested.

\section{Antibiotic susceptibility}

Penicillinase production was tested for by the use of the chromogenic cephalosporin, Nitrocefin (Oxoid). The MIC to penicillin of non-penicillinase producing strains was determined using an agar dilution technique. The medium used was Diagnostic Sensitivity Test (DST) Agar (Oxoid) containing 1\% IsoVitaleX and 5\% lysed horse blood (Tissue Culture Services). Penicillin was added as Adatabs (Mast Diagnostics Ltd) between $4 \cdot 0-0.008 \mathrm{mg} / 1$. The inoculum was prepared from an overnight culture of each strain on GC agar base (Difco) supplemented with $1 \%$ IsoVitaleX. A cloudy suspension was made in saline, read at $540 \mathrm{~nm}$ and adjusted to an optical density of 1.0 giving approximately $10^{8}$ colony forming units $(\mathrm{cfu}) / \mathrm{ml}$. One microlitre volumes $\left(10^{5} \mathrm{cfu}\right)$ were inoculated onto antibiotic containing media using a multipoint inoculator (Denley). In early experiments a laboratory strain of known susceptibility was used to control each batch and more recently we have used the World Health Organization control strains A-E. The point of complete inhibition was read after 48 hours at $36^{\circ} \mathrm{C}$ in $7 \%$ carbon dioxide. One or two colonies were scored as growth. Strains of nonPPNG with a MIC $\geq 1.0 \mathrm{mg} / 1$ were considered CMRNG and those exhibiting a MIC of $\leq 0.5 \mathrm{mg} / 1$ were considered penicillin sensitive. This latter group included both strains which showed intermediate levels of resistance (MIC, $\leq 0.5-0.12 \mathrm{mg} / \mathrm{l}$ ) and penicillin sensitive strains (MIC, $\leq 0.06 \mathrm{mg} / \mathrm{l}$ ), all of which would be considered therapeutically sensitive to penicillin.

\section{Plasmid analysis}

Plasmids were extracted using the alkali method of Birnboim and Doly, ${ }^{20}$ electrophoresed on $1 \%$ agarose and visualised using ethidium bromide.

\section{Statistical analysis}

Differences in the distribution of serovars in groups of strains of varying penicillin susceptibility were determined using chi square test.

Table 1 Distribution of serogroup and predominant serovars among penicillin sensitive strains (830), CMRNG (100) and PPNG carrying 4.4 MDa (429) or $3 \cdot 2 \mathrm{MDa}(220)$ plasmid

\begin{tabular}{|c|c|c|c|c|}
\hline & Penicillin sensitive & $\begin{array}{c}\text { (Number of strains, \% of total) } \\
C M R N G\end{array}$ & $P P N G 4.4 M D a$ & PPNG 3.2 MDa \\
\hline $\begin{array}{l}\text { Serogroup } \\
\text { IA } \\
\text { IB }\end{array}$ & $\begin{array}{l}259(31) \\
571(69)\end{array}$ & $\begin{array}{l}10(10) \\
90(90)\end{array}$ & $\begin{array}{l}118(28) \\
311(72)\end{array}$ & $\begin{array}{r}127(58) \\
93(42)\end{array}$ \\
\hline $\begin{array}{l}\text { Serovars } \\
\text { IA-1/2 } \\
\text { IA-4 } \\
\text { IA-6 } \\
\text { IA-10 } \\
\text { IB-1 } \\
\text { IB-2 } \\
\text { IB-3 } \\
\text { IB-5/7 }\end{array}$ & $\begin{array}{c}197(24) \\
11(1) \\
17(2) \\
11(1) \\
117(14) \\
127(15) \\
158(19) \\
25(3)\end{array}$ & $\begin{array}{c}6(6) \\
0(0) \\
1(1) \\
1(1) \\
25(25) \\
4(4) \\
28(28) \\
18(18)\end{array}$ & $\begin{array}{c}16(4) \\
5(1) \\
88(21) \\
5(1) \\
106(25) \\
12(3) \\
21(5) \\
147(33)\end{array}$ & $\begin{array}{c}59(27) \\
27(12) \\
17(8) \\
19(9) \\
30(14) \\
6(3) \\
8(4) \\
30(14)\end{array}$ \\
\hline
\end{tabular}


Table 2 Distribution of predominant auxotypes among penicillin sensitive strains (830), CMRNG (100) and PPNG carrying the 4.4 MDa (429) or 3.2 MDa (220) plasmid

\begin{tabular}{|c|c|c|c|c|}
\hline Auxotype & Penicillin sensitive & $\begin{array}{c}\text { (Number of strains, } \% \text { of total) } \\
\text { CMRNG }\end{array}$ & PPNG 4.4 MDa & $P P N G 3 \cdot 2 \mathrm{MDa}$ \\
\hline $\begin{array}{l}\text { NR } \\
\text { Pro } \\
\text { AHU } \\
\text { Arg } \\
\text { PAOU } \\
\text { PA }\end{array}$ & $\begin{array}{c}337(41) \\
128(15) \\
148(18) \\
95(11) \\
48(6) \\
34(4)\end{array}$ & $\begin{array}{c}66(66) \\
20(20) \\
2(2) \\
4(4) \\
1(1) \\
1(1)\end{array}$ & $\begin{array}{c}129(30) \\
285(66) \\
0 \\
3(1) \\
0 \\
9(2)\end{array}$ & $\begin{array}{c}101(46) \\
49(22) \\
0 \\
31(14) \\
0 \\
24(11)\end{array}$ \\
\hline
\end{tabular}

NR $=$ non-requiring

Pro $=$ proline requiring

AHU $=$ Arginine, hypoxanthine and uracil requiring

Arg = Arginine but not ornithine requiring

PAOU = Proline, arginine, ornithine and uracil requiring

$\mathrm{PA}=$ Proline and arginine requiring

\section{Results}

Eight hundred and forty of the 1589 strains of $N$ gonorrhoeae we investigated were penicillin sensitive and 100 showed chromosomal resistance (CMRNG); 429 were PPNG which carried the $4.4 \mathrm{MDa}$ plasmid while 220 were PPNG with the $3 \cdot 2 \mathrm{MDa}$ plasmid. The distribution of strains between serogroup IA and IB is shown in table 1. CMRNG were significantly more common in serogroup PIB than penicillin sensitive strains $(p=<0.001)$. The overall serogroup distribution of PPNG with the $4.4 \mathrm{MDa}$ plasmid was apparently similar to that of penicillin sensitive strains. PPNG with the $3.2 \mathrm{MDa}$ plasmid were the only group in which serogroup PIA strains were more common than those of serogroup PIB. This distribution was significantly different from that found in the PPNG with the 4.4 MDa plasmid and both the groups of nonPPNG $(p=<0.001)$.

The penicillin sensitive strains could be divided into 40 serovars, the CMRNG into 15 serovars, PPNG with 4.4 MDa plasmid belonged into 20 serovars and PPNG with 3.2 MDa plasmid into 19 serovars. Although serovar IA-1/2 is more common among penicillin sensitive strains there was no difference between the distribution of PIA serovars between penicillin sensitive strains and CMRNG $(p=0 \cdot 7)$. However, there was a significant difference in PIB serovars $(p=<0.001)$, table 1 . Serovar IB$5 / 7$ occurred more frequently among CMRNG but serovar IB-2 was more prevalent among penicillin sensitive strains. Serovars IB-1 and IB-3 were predominant in both groups. The distribution of PIA serovars differed significantly between the two PPNG groups $(p=<0.001)$, serovar IA-6 was most prevalent among $4.4 \mathrm{MDa}$ plasmid carrying strains whereas IA-1/2 was most common among $3 \cdot 2$ $\mathrm{MDa}$ plasmid carrying strains. PIB serovars were more evenly distributed in both types of strains but significantly more PPNG with $4.4 \mathrm{MDa}$ plasmid belonged to serovars IB-1 $(p=<0.001)$ and IB-5/7 $(\mathrm{p}=0.01)$.

Penicillin sensitive strains could be divided into 19 auxotypes and four auxotypes, non-requiring (NR), proline (pro), arginine (arg) and arginine, hypoxanthine and uracil (AHU) requiring accounted for 708 of the 840 strains ( $85 \%$ ). CMRNG were divided into ten auxotypes but only two auxotypes, NR and pro, accounted for $86 \%$ of strains. Penicillin sensitive and CMRNG strains were both predominantly proline or non-requiring but there were significantly more penicillin sensitive strains required either AHU or arginine but not ornithine ( $\mathrm{arg})(\mathrm{p}=<0.001)$.

PPNG strains with either the $4 \cdot 4 \mathrm{MDa}$ or $3.2 \mathrm{MDa}$ plasmid could be divided into seven auxotypes but 414 of $439(94 \%)$ PPNG with $4.4 \mathrm{MDa}$ plasmid were either NR or Pro (table 2) whereas PPNG with 3.2 MDa plasmid were more evenly distributed between NR, pro, arg and pro, arg which accounted for 205 of

Table 3 Distribution of the predominant PIA A/S Classes among penicillin sensitive strains (259), CMRNG (10) and PPNG carrying 4.4 MDa (118) or 3.2 MDa (127) plasmid

\begin{tabular}{|c|c|c|c|c|}
\hline$A / S$ Class & Penicillin sensitive & $\begin{array}{l}\text { (Number, } \% \text { of } 1 A \text { strains) } \\
\text { CMRNG }\end{array}$ & $P P N G 4.4 \mathrm{MDa}$ & $P P N G 3.2 \mathrm{MDa}$ \\
\hline $\begin{array}{l}\text { NR/IA-1/2 } \\
\text { Pro/IA-1/2 } \\
\text { AHU/IA-1/2 } \\
\text { Arg/IA-1/2 } \\
\text { NR/IA-4 } \\
\text { Pro/IA-6 } \\
\text { Pro/IA-10 }\end{array}$ & $\begin{array}{c}26(10) \\
4(2) \\
130(50) \\
8(3) \\
8(3) \\
5(2) \\
1(<1)\end{array}$ & $\begin{array}{l}3(33) \\
0 \\
3(33) \\
0 \\
0 \\
0 \\
0\end{array}$ & $\begin{array}{l}8(7) \\
8(7) \\
0 \\
0 \\
4(3) \\
66(56) \\
4(3)\end{array}$ & $\begin{array}{c}16(13) \\
12(9) \\
0 \\
15(12) \\
18(14) \\
8(6) \\
11(9)\end{array}$ \\
\hline
\end{tabular}


Table 4 Distribution of the predominant PIB A/S Classes among penicillin sensitive strains (571), CMRNG (90) and PPNG carrying 4.4 MDa (311) or 3.2 MDa (93) plasmid

\begin{tabular}{|c|c|c|c|c|}
\hline$A / S$ Class & Penicillin sensitive & $\begin{array}{c}\text { (Number, \% of } 1 B \text { strains) } \\
\text { CMRNG }\end{array}$ & $P P N G 4.4 M D a$ & $P P N G 3 \cdot 2 \mathrm{MDa}$ \\
\hline $\begin{array}{l}\text { NR/IB-1 } \\
\text { Pro/IB-1 } \\
\text { PA/IB-1 } \\
\text { NR/IB-2 } \\
\text { PAOU/IB-2 } \\
\text { NR/IB-3 } \\
\text { Arg/IB-3 } \\
\text { NR/IB-5/7 } \\
\text { Pro/IB-5/7 }\end{array}$ & $\begin{array}{c}47(8) \\
38(7) \\
9(2) \\
47(8) \\
34(6) \\
92(16) \\
42(7) \\
15(3) \\
8(1)\end{array}$ & $\begin{array}{c}11(12) \\
9(10) \\
0 \\
1(1) \\
0 \\
24(27) \\
1(1) \\
12(13) \\
4(4)\end{array}$ & $\begin{array}{l}19(6) \\
81(26) \\
0 \\
3(1) \\
0 \\
2(1) \\
0 \\
61(20) \\
83(27)\end{array}$ & $\begin{array}{c}14(15) \\
6(7) \\
8(9) \\
8(9) \\
0 \\
1(1) \\
5(5) \\
14(15) \\
14(15)\end{array}$ \\
\hline
\end{tabular}

$220(93 \%)$ strains. PPNG with $4.4 \mathrm{MDa}$ plasmid were predominantly proline requiring whereas PPNG with the $3.2 \mathrm{MDa}$ plasmid were more often NR or arginine requiring ( $\mathrm{p}=<0.001)$. Both $\mathrm{AHU}$ and proline, arginine, ornithine and uracil (PAOU) requiring strains were not found amongst the PPNG tested and were rare among the CMRNG (table 2).

A total of 126 auxotype/serovar (A/S) classes was found among penicillin sensitive strains compared to $34 \mathrm{~A} / \mathrm{S}$ classes among CMRNG, 38 among PPNG with 4.4 MDa plasmid and 40 among PPNG with 3.2 MDa plasmid. All PIA A/S classes were uncommon among CMRNG whereas AHU/IA-1/2 accounted for 197 of 840 penicillin sensitive strains (table 3 ). The distribution of PIA $\mathrm{A} / \mathrm{S}$ classes differed significantly between the two groups of PPNG $(\mathrm{p}=<0.001)$. The A/S class pro/IA-6 accounted for 66 of $118(56 \%)$ PIA strains of PPNG with 4.4 MDa plasmid compared with strains of PPNG with 3.2 MDa plasmid which were divided between $\mathrm{A} / \mathrm{S}$ classes, NR/IA-1/2, pro/IA-1/2, $\arg / \mathrm{IA}-1 / 2, \mathrm{NR} /$ IA-4 and pro/IA-10 and together accounted for 72 of $127(57 \%)$ of strains. The A/S class, AHU/IA-1/2 was not found among PPNG.

PIB A/S classes, NR/IB-3 and NR/IB-5/7 were more prevalent among CMRNG than penicillin sensitive strains $(p=0.02)$, table 4 . PPNG with the 4.4 MDa plasmid belonged to pro/IB-1, NR/IB-5/7 and pro/IB-5/7 significantly more often than PPNG with the $3.2 \mathrm{MDa}$ plasmid $(\mathrm{p}=0.001)$. In contrast, strains belonging to NR/IB-1 were more prevalent among PPNG with $3.2 \mathrm{MDa}$ plasmid ( $\mathrm{p}=0.01$ ).

\section{Discussion}

We have used serological classification and auxotyping to investigate whether certain strains of $N$ gonorrhoeae are associated with penicillin resistance either chromosomal or plasmid mediated. Some patterns are clear. We have confirmed previous reports that most CMRNG strains belong to serogroup PIB and serogroup PIA strains are found more commonly among penicillin sensitive $N$ gonorrhoeae. $^{141521}$ The monoclonal antibodies used to deter- mine the gonococcal serogroup are raised to epitopes on the two types of the major outer membrane protein, PI, which acts as a porin. The locus por has not been thought to have a direct role in antibiotic resistance but to be closely linked to the locus pen $B$ which is responsible for low level increases in resistance to penicillin and tetracyline. ${ }^{1}$ Carbonetti et $a l^{22}$ have recently demonstrated that transfer of certain cloned PIB genes into PIA strains confers not only a change in serogroup but small increases in penicillin resistance. This finding raises the possibility that the loci por and pen $B$ may be the same, in which case there would be a major role for $P I$ in resistance to penicillin. We have found that serovar IB-5/7 strains are strongly associated with resistance whereas other serovars such as serovar IB-2 are not. It is possible that epitopes detected by the antibodies defining IB$5 / 7$ serovar may reflect the part of the por locus involved in antibiotic resistance.

The presence of serovar IA-1/2 and requirement for AHU, particularly when found together, are strongly associated with hypersensitivity to penicillin. The mechansim for this is unknown but could be related to the PIA type of the porin. We have found arginine requirement to confer increased sensitivity to penicillin on all serovars but the mechanism is unknown.

PPNG carrying a $4.4 \mathrm{MDa}$ plasmid have been described as exhibiting higher levels of chromosomal resistance and PPNG with $3.2 \mathrm{MDa}$ plasmid as showing a greater degree of susceptibility. ${ }^{23}$ The increased prevalence of serovar IB-5/7 in our population of $4.4 \mathrm{MDa}$ carrying strains and of serovar IA-1/2 among 3.2 $\mathrm{MDa}$ carrying PPNG supports previous findings. However, the pattern is more complex. Seventy-five per cent of serogroup IA. isolates within PPNG with 4.4 MDa plasmid were serovar IA-6, a IA serovar that in comparison with IA-1/2 appears to be associated with reduced susceptibility to penicillin (unpublished observation). However, this prominent cluster of IA-6 isolates could also result from the introduction of the 4.4 MDa plasmid into a IA-6 strain followed by the spread of that single strain. The majority of the 
PPNG that belonged to serovar IA-6 were also proline requiring and were isolated between 1983$85 .^{16}$

Penicillinase plasmids are acquired during conjugation in Ngonorrhoeae. Acquisition of plasmids by transformation is inefficient and species restricted ${ }^{24}$ and not believed to be important in vivo. The transfer of the penicillinase plasmids is dependant on the presence of the $24.5 \mathrm{MDa}$ conjugative plasmid in the donating strain. However, it is possible that acceptance of penicillinase encoding plasmids is also restricted. Strains requiring PAOU or AHU have not been reported among PPNG. In conjugation experiments in vitro the $3.2 \mathrm{MDa}$ and $4.4 \mathrm{MDa}$ plasmids have been transferred to AHU requiring strains but not to PAOU requiring strains. ${ }^{25}$ This could be linked to the absence of the $2.6 \mathrm{MDa}$ cryptic plasmid in PAOU strains although strains belonging to other A/S classes also missing the cryptic plasmid were able to accept the plasmids. Experiments to investigate the effect of serovar on acceptance of the $3.2 \mathrm{MDa}$ or $4.4 \mathrm{MDa}$ plasmids have shown no detectable difference. ${ }^{25} 26$

Although some clear associations have been demonstrated, the patterns particularly among PPNG seem more complex. The use of greater discrimination of $\mathrm{A} / \mathrm{S}$ classes has not enhanced the information given either by the serovar or the auxotype. A/S classes are most useful for tracing contacts of gonorrhoea when fine discrimination is necessary. The PPNG population we have studied consist of a small number of predominant clusters such as the pro/IA-6, 4.4 MDa PPNG. These clusters may, even in our diverse population, be the spread of a single strain in a limited time span. Epidemiological clusters bias this type of analysis and can probably only be overcome by the use of strains from many different geographical areas and of differing penicillin susceptibility.

We thank Jill Gedney, Neil Woodford and Khalid Bindayna for technical assistance and Syva Co, Palo Alto for the gift of the monoclonal antibodies.

1 Cannon JG, Sparling PF. The genetics of the gonococcus. Ann Rev Microbiol 1984;38:111-33.

2 Reyn A, Korner B, Benzton MW. Effects of penicillin, streptomycin and tetracycline on Neisseria gonorrhoeae isolated in 1944 and 1957. Br J Venereal Dis 1958;34:227-39.

3 Phillips I. B-lactamase-producing, penicillin-resistant gonococcus. Lancet 1976;ii656-7.

4 Percival A, Rowlands J, Corkhill JE, et al. Penicillinaseproducing gonococci in Liverpool. Lancet 1976;ii:1379-82.
5 Centers for Disease Control. Penicillinase-producing Neisseria gonorrhoeae. Morbidity and Mortality Weekly Report 1976; 25:261.

6 Ashford WA, Golash RG, Hemming VG. Penicillinase-producing Neisseria gonorrhoeae. Lancet 1976; ;i:657-8.

7 Perine PL, Thornesberry C, Schalla W, Biddle J, Siegel MS, Wong K-H, Thompson S. Evidence for two distinct type of penicillinase-producing Neisseria gonorrhoeae. Lancet 1977; ii:993-5.

8 Ison CA, Gedney J, Easmon CSF. Chromosomal resistance of gonococci to antibiotics. Genitourin Med 1987;63:239-43.

9 Rice RJ, Biddle JW, JeanLouis YA, DeWitt WE, Blount JH, Morse SA. Chromosomally-mediated resistance in Neisseria gonorrhoeae in the United States: results of surveillance and reporting, 1983-4. J Infect Dis 1986;153:340-5.

10 Faruki H, Kohmescher RN, McKinney WP, Sparling PF. A community-based outbreak of infection with penicillin-resistant Neisseria gonorrhoeae not producing penicillinase (chromosomally-mediated resistance). $N$ Engl J Med 1985;313:607-11.

11 Tam MR, Buchanan TM, Sandstrom EG, et al. Serological classification of Neisseria gonorrhoeae with monoclonal antibodies. Infect Immun 1982;36:1042-53.

12 Knapp JS, Tam MR, Nowinski RC, Holmes KK, Sandstrom EG. Serological classification of Neisseria gonorrhoeae with the use of monoclonal antibodies to gonococcal outer membrane protein I. J Infect Dis 1984;150:44-8.

13 Kohl PK, Ison CA, Danielsson D, Knapp JS, Petzold D. Current status of serotyping of Neisseria gonorrhoeae. Eur $J$ Epidemiol 1990;6:91-5.

14 Gill MJ. Serotyping Neisseria gonorrhoeae. A report of the Fourth International Workshop. Genitourin Med 1991;67: 53-7.

15 Woodford N, Bindayna KM, Easmon CSF, Ison CA. Associations between serotype and susceptibility to antibiotics of Neisseria gonorrhoeae. Genitourin Med 1989;65:86-91.

16 Ison CA, Easmon CSF. Changes in penicillinase-producing Neisseria gonorrhoeae isolated in London. J Med Microbio 1989;30:239-44.

17 Bindayna KM, Easmon CSF, Ison CA. Chromosomal resistance to antibiotics in Bahrain. Sex Trans Dis. (In press.)

18 Bindayna KM, Ison CA. Sampling methods for monitoring changes in gonococcal populations. Epid Infect 1989;103 203-9.

19 Copley CG, Egglestone SI. Auxotyping of Neisseria gonorrhoeae isolated in the United Kingdom. J Med Microbiol 1983; 16:295-302.

20 Birnboim HC, Doly J. A rapid alkaline extraction procedure for screening recombinant plasmid DNA. Nucleic Acid Res 1979;7:1513-23.

21 Bygdeman SM. Polyclonal and monoclonal antibodies applied to the epidemiology of gonococcal infection. In: Young $\mathbf{H}$, McMillan A eds. Immunological Diagnosis of Sexually Transmitted Diseases. New York: Marcel Dekker Inc. 1988:117-165.

22 Carbonetti N, Simnad V, Elkins C, Sparling PF. Construction of isogenic gonococci with variable porin structure: effects on susceptibility to human serum and antibiotics. Mol Microbiol 1990;4:1009-18.

23 Ison CA, Gedney J, Harris JRW, Easmon CSF. Penicillinase producing gonococci: a spent force? Genitourin Med 1986; 62:302-7.

24 Biswas GD, Graves JF, Sox TE, Tenover FC, Sparling PF. Marker rescue by a homologous recipient plasmid during transformation of gonococci by a hybrid Pc plasmid. $J$ Bacteriol 1982;151:77-82.

25 Sarafian SK, Genco CA, Roberts MC, Knapp JS. Acquisition of B-lactamase and Tet-M containing conjugative plasmids by phenotypically different strains of Neisseria gonorrhoeae. Sex Transm Dis 1990;17:67-71.

26 Ison CA, Gill MJ, Woodford N. Transfer of beta-lactamase plasmids by conjugation in Neisseria gonorrhoeae. Genitourin Med 1990;66:82-6. 